\title{
Blood albumin level in cases with colorectal cancer
}

Viroj Wiwanitkit

Accepted: 11 April 2011 /Published online: 19 April 2011

(C) Springer-Verlag 2011

\section{Dear Editor:}

I read the recent publication on blood albumin level in cases with colorectal cancer with great interest (Int $J$ Colorectal Dis 2011 Apr; 26(4):469-72). McCutchen et al. demonstrated a lower level in a studied group and further extrapolated on nutritional status and nutritional management for decrease disparities of outcome between groups. There are some concerns. First, the measured albumin is only a part of nutritional status assessment. It can reflect only a partial view not the full view of nutritional status. Second, the laboratory data from database review might imply no quality control on the laboratory technique. At least, it can be questionable whether the technique and condition for the determination of all albumin tests was the same. Finally, the note on aggressive nutritional interventions to reverse the disparity has to be carefully considered. This might lead to the inequity in clinical practice. Indeed, the standard guideline for nutritional management can be used and should be applied for all cases.

V. Wiwanitkit $(\bowtie)$

Wiwanitkit House, Bangkhae,

Bangkok 10160, Thailand

e-mail: wviroj@yahoo.com 